\title{
A EXPERIÊNCIA COMO INTERVALO PARA NOVAS VISIBILIDADES
}

\author{
Eliana Dable de Mello \\ Edson André Luiz de Sousa \\ Universidade Federal do Rio Grande do Sul
}

RESUMO: Compreendendo, com Foucault, o campo discursivo como campo de disputa da hegemonia dos sentidos, o texto questiona as verdades produzidas pela lógica dominante no sistema capitalista e propõe a experiência como possibilidade de singularização do olhar que ilumina as formas produzidas na cultura. Analisa, nesta perspectiva, as diferentes conseqüências relacionadas às diferentes posições do olhar e sublinha, na abertura ao invisível, pressuposta à configuração da imagem em sua condição dialética, o intervalo capaz de dar lugar ao novo.

PALAVRAS-CHAVE: posição do olhar; imagem dialética; experiência, subjetividade.

\section{THE EXPERIENCE WHILE INTERVAL FOR NEW VISIBILITIES}

ABSTRACT: Understanding, with Foucault, the discursive field as field of dispute of the hegemony of the senses, the text questions the truths produced by the dominant logic in the capitalist system and it proposes the experience as possibility of singularity of the glance that illuminates the forms produced in the culture. It analyzes, in this perspective, the different consequences related to the different positions of the glance and underscores, in the opening to the invisible, presupposed to the configuration of the image in its dialectic condition, the interval that is capable to give place to the new.

KEY-WORDS: position of the glance; dialectic image; experience, subjectivity.

O reverso do conhecido, suas costas, são para mim estas ruas penúltimas, quase tão efetivamente ignoradas como o alicerce soterrado de nossa casa ou nosso invisível esqueleto.

Jorge Luis Borges, "História da Eternidade".

Toda escrita que busca uma tomada de posição no campo do discurso exige um trabalho prévio de esvaziamento dos enunciados que se cristalizaram como verdades, pois as verdades dos especialistas, baseadas na evidência de regularidades sujeitas à replicação, e corriqueiramente reprocessadas pela mídia, apresentam-se como naturalizadas certezas. Estas pretendem tudo saber sobre os acontecimentos do mundo, e nos deixam escassas brechas onde possamos insinuar o acaso e a singularidade dos eventos que presenciamos ou de que participamos, e que com outros compartilhamos, temporalizados em um presente que transversaliza o passado assim como o futuro.

Por esta via, queremos abrir algumas questões: quantas lógicas, em seu sentido lato, regem nosso mundo humano? Em quantas posições discursivas as linguagens reverberam, produzindo diferentes efeitos de sentido? Da lógica da linguagem técnico-informacional, de razão instrumental, à da palavra poética, de razão sensível, é no regis- tro da multiplicidade que testemunhamos sua existência. Falamos em lógica da ciência, do inconsciente, do mercado, da globalização, do espetáculo, dos discursos, entre tantas outras. A melhor imagem que encontramos para expressá-la é a da alegoria, no sentido benjaminiano ${ }^{1}$, pois nos permite compreender a lógica enquanto indeterminação plural, embora talvez não infinita, como nos sugere Nietzsche (1987) ao falar das forças que atuam no mundo, mas dependente das formas, visíveis e invisíveis, para revelar seus múltiplos sentidos e racionalidades.

\section{O OLHAR E SUAS DERIVAÇÕES}

Especialista, espectador, especulador, especular, espectro, espetáculo, são algumas das palavras que têm sua origem na raiz spec, que significa olhar. Será que todos olhamos o mundo da mesma forma, mesmo numa mesma época? Será que nosso próprio eu olha o mundo sempre do mesmo modo? O filósofo e fotógrafo Evgen Bavcar (2001) 
Mello, E.D.; Sousa, E.A.L."A experiência como intervalo para novas visibilidades"

busca nas figuras míticas do universo greco-romano uma história do olhar em suas formas mais primitivas, e propõe tomarmos Ciclope, Ulisses, Tirésias e Argus para narrá-la. O Ciclope, provido de um olho só, interpretando a primitiva e rudimentar visão instintiva, vê o mundo de maneira unidimensional, apegado ao todo da natureza; por isso, para ele, o mundo ainda se apresenta dotado de unidade paradisíaca. Este é justamente derrotado por Ulisses e sua visão binocular, que, podendo diferenciar o nome da coisa, astuciosamente se nomeia como Ninguém, a quem o Ciclope denunciará aos seus irmãos como o autor do ato que o cegou (Ninguém o cegou), permitindo a Ulisses escapar mais uma vez. O sacrifício da visão do Ciclope, para Bavcar, paga o privilégio de não se olhar permanentemente a mesma coisa, de criarmos distância para pensarmos o mundo, sem cairmos na fatalidade mítica. Afirma o autor que, com Ulisses, surge o olhar ligado ao saber, que não seria, no entanto, muito mais do que isso, sendo a visão comum que vê o que sabe: distinguir entre o significante e o significado, o objeto e seu signo, a pessoa e seu nome. Será com Édipo, e mais ainda com Tirésias, que, cegos, vêem o passado e o futuro no presente, que o olhar se expandirá para o invisível. Quanto a Argos, também chamado Panoptes, o monstro de cem olhos - dos quais só cinqüenta adormecem, de cada vez - seria a encarnação da vigilância permanente.

É inegável que nosso mundo contemporâneo, herdeiro das proposições iluministas e fundado na ciência, privilegia o olhar que aqui atribuímos a Ulisses - sem com isso, obviamente, pretendermos atrelar a riqueza desse mito a esse único sentido - que permite separar e classificar, ordenar categorias e normatizar o real, enquanto pretende erradicar o erro, negar a incompletude e os intervalos que suspendem as certezas: Exige-se da imagem, referência a um real visível. O olho escravizado quer a lógica figurativa, a representação do real. As imagens, exigidas à contenção, precisam ser verificáveis a qualquer preço (TIMM, 2003). Aparentemente, tudo é visível e reconhecível; mesmo nossa intimidade passa a ser cada vez mais falada e mostrada, e câmaras nos perscrutam desde o céu ou do interior dos prédios - qual Argos tecnológicos cumprindo com total eficácia a função de vigilância do Panóptico.

Neste sentido, toma grande relevância a afirmação de Hannah Arendt (2001) de que a invenção do telescópio, por criar condições de possibilidade para o encolhimento do espaço e a abolição das distâncias é um dos três grandes eventos que determinaram o caráter da era moderna - os outros dois seriam o descobrimento da América e a Reforma -, e que o preço dessa conquista, associada aos outros eventos, foi a alienação do homem de seu ambiente imediato e terreno. Para Arendt, o pressuposto básico de toda a ciência moderna, a separação entre o ser e a aparência, levou ao descrédito do conhecimento trazido pelos sentidos como um todo - reunidos e presididos pelo senso comum, que é o sexto e o mais alto de todos os sentidos (p. 287), acarretando que tudo deve ser posto em dúvida, só sendo verdade aquilo que a ciência comprova. Em vista disso, diz, os cientistas formulam hipóteses para conciliar seus experimentos e em seguida empregam estes experimentos para verificar as hipóteses (p.300), sempre lidando, portanto, com uma natureza hipotética, demasiadamente afastada de nós para fazer parte de nossa experiência. Paradoxalmente, um mundo regido pela lógica dominante da verdade da ciência acabou nos lançando irremediavelmente na dúvida que irrealiza o mundo, e onde o senso comum foi esvaziado de qualquer sabedoria, transformando-se no campo de meras familiaridades e consenso.

\section{A LÓGICA DOMINANTE E A SINGULARIZAÇÃO}

O predomínio dessa lógica mostrou-se imprescindível na consolidação da formação social capitalista, e, para a sociedade de consumidores vitória do animal laborans - por ela produzida, o valor da existência deslocou-se para a sobrevalorização da fabricação e posse dos objetos. No ofuscamento de um mundo público compartilhado, a relação com o objeto, que vinha mediada pela relação a alguma referência terceira, vai, aos poucos, prescindindo desta presença simbólica (MELMAN, 1992). Ao tornar-se dual, fetichiza o objeto e, ao mesmo tempo, reifica os homens, do que resulta a formação de uma sociedade de indivíduos em compulsiva e imperativa busca pelo bem estar, dispostos a comprar a felicidade a qualquer preço.

Dessa forma, um sistemático assujeitamento da experiência subjetiva é implementado pela estratégia de equivalência de todos os valores a um valor estético-utilitário de mercadoria, enquanto a identidade passa a ser definida pela imagem associada à posse de cambiantes objetos oferecidos como insígnias do sucesso. A magnitude prescritiva de nossa sociedade de controle (DELEUZE, 1992) que aperfeiçoou todos dispositivos disciplinares (FOUCAULT, 2002b) para individualização e docilização dos corpos no espaço e no tempo - configura-se, portanto, como um modo de captura da subjetividade que direciona a percepção humana através da particularização de imagens e enuncia- 
dos enquanto definidores da realidade.

Todos sabemos que o desenvolvimento tecnológico sofisticou, de forma antes impensada, esse controle, principalmente através da mídia, que se encarregou da domesticação dos corpos de forma imaterial. O que vestir, o que comer, como amar, que corpo exibir, como ser mulher, homem, jovem, velho ou criança são, afinal, hoje, assuntos recorrentes e privilegiados nos meios de comunicação. Fischer (2002, p.86) aponta, nesse sentido, que

Mais do que inventar ou produzir um discurso, a mídia reduplica-lo-ia, porém sempre a seu modo, na sua linguagem, na sua forma de tratar aquilo que 'deve' ser visto ou ouvido. Isto quer dizer então que ela também estaria simultaneamente replicando algo e produzindo seu próprio discurso, sobre a mulher, sobre a criança, sobre o trabalhador [...] sobre a juventude ou a adolescência.

Uma cultura midiática do consenso vem assim, gradualmente, produzindo o empobrecimento das narrativas pela imposição da linguagem prático-comunicativa da informação, que desloca o sentido da transitoriedade - como experiência temporal - para a vivência psicológica de sucessivas aventuras descontínuas (GAGNEBIN, 1994). É dessa forma que vamos sendo modulados enquanto indivíduos narcísicos, buscando soluções também individualizadas para os problemas coletivos e visando ao reconhecimento imediato de nosso valor, sobretudo como imagem corporal. E o corpo jovem se coloca aqui não apenas como o grande ideal estético a que todos temos que nos submeter, mas também como o grande alvo da sedução capitalista, por sua particular predisposição a consumir os produtos culturais que vão sendo freneticamente lançados no mercado por criativas estratégias de propaganda e marketing.

No entanto, não podemos esquecer que o mundo humano é construído de significações ancoradas no trânsito da linguagem - em que os significados, portanto, não podem ser definitivamente fixados. Foucault nos ensinou que é no campo discursivo que se tramam as disputas da hegemonia do sentido e seus lugares de validação. São os enunciados prevalentes de uma época - captados nos murmúrios que provocam - que conformam os ideais que nortearão as práticas exercidas socialmente, numa relação de mão dupla que, ao mesmo tempo em que fixa, transforma os próprios enunciados, relançando constantemente as significações. É desta forma que entendemos que linhas de fuga aos discursos dominantes não possam ser definitivamente evitadas pelo exercício do poder: pois se existem relações de poder através de todo campo social, é porque em toda parte há liberdade (FOUCAULT, 1999). A unicidade de cada momento está sempre a produzir frestas virtualmente prenhes para a singularização do olhar e da palavra, revelando-se como potência de resistência à ordem dominante. É importante considerar, para isso, que o singular não se atém ao individual, pois o individual se sustenta na ilusão da autonomia, enquanto o singular faz parte de uma formação coletiva em que os traços fazem a inscrição da diferença. Embora na linguagem comum costuma-se dizer que a individualidade é o que marca a presença de traços originais que distinguem as pessoas uma das outras, a massificação de padrões apóia-se justamente na noção de indivíduo - perpassada através de uma multiplicidade de normas, regras e práticas que propõem determinados modos de relação consigo que buscam, sobretudo, o equilíbrio e a medida que pretende anular as contradições.

\section{O CORPO E A LÓGICA DE EXCITAÇÃO TÉCNICA: A SUBJUGAÇÃO DA SUBJETIVIDADE}

Parece que à inquietante pergunta sobre quem somos cuja resposta fomos instados a construir laboriosamente, com peculiar urgência desde o advento da modernidade, pelo nosso desamparo frente à perda das referências tradicionais que nos posicionavam de forma mais estável na organização social -, a contemporaneidade, ao travestir os dispositivos biopolíticos de regulação do poder, nos oferece uma possibilidade de resposta que poupa qualquer trabalho subjetivo. Diz que somos um corpo em constante trabalho de manutenção e aperfeiçoamento de suas partes. A indução do culto ao corpo vem a configurar a dupla captura do indivíduo ao que Guattari e Rolnik (1986) chamam de modo capitalístico ${ }^{2}$ de subjetivação: ao mesmo tempo em que neutraliza seu potencial subversivo à ordem vigente, fomenta o consumo da parafernália estética que promete a perfeição das formas e a potência corporal que sustentarão a ilusão de beleza, vigor e juventude eternos, enquanto afiançam concretamente a saúde do soberano Mercado. A hegemonia da lógica de excitação técnica que se dissemina em todos os campos da sociedade atual encontra, portanto, no corpo, seu principal suporte, e produz uma força de achatamento das singularidades da experiência ao provocar a estandardização de todos valores. Dessa forma, ao concebermos a subjetividade como produção do Outro $^{3}$, podemos dar visibilidade à tendência das sociedades capitalísticas em bloquear processos de 
Mello, E.D.; Sousa, E.A.L."A experiência como intervalo para novas visibilidades"

singularização e engendrar processos de individualização que nos insensibilizam para o reconhecimento das diferenças.

É certo que, com estas colocações, poderíamos agora cair na tentação de entoar a ladainha dos horrores a que estamos destinados quando esta lógica totalitária triunfa, baseados nos terríveis exemplos, passados e presentes, que a história nos oferece. Mas nossa intenção, com essa reflexão, é abrir algumas trilhas que possam nos levar ao reconhecimento do novo - entendido aqui como abertura para o desconhecido - e não demonizar o que quer que seja. E não pretendemos esquecer que a ciência, a tecnologia, ou mesmo a mídia, também podem estar voltadas ao interesse do bem-comum e à proposição de bens culturais de valor inestimável: entendemos que a perversidade da lógica que engendra seus mecanismos de inclusão e exclusão - de controle e instrumentalização, em suma - é que deve ser criticada. Além disso, a hegemonia de uma lógica de subjetivação não a legitima como única, pois seria como tomarmos uma parte, por maior que ela seja, pelo todo, sucumbindo ao fascínio de suas produções discursivas, que relegam outras possibilidades de olhar, portadoras de outras lógicas e de outras racionalidades dotadas de força sensível, ao limbo da obscuridade.

\section{A CISÃO DA IMAGEM E A POSIÇÃO DO OLHAR}

Tomando o olhar como metáfora de nossa potencialidade perceptiva, apontamos que o obscuro não é inexistente - isso a arte e a psicanálise estão constantemente a nos confirmar -, embora o sentido da visão não seja suficiente para figurá-lo, pois a experiência do ato de olhar é também dependente do que em nós faz memória. Walter Benjamin, conforme Didi-Huberman (1998), propõe o conceito de imagem dialética como aquela capaz de sustentar o paradoxo de oferecer uma figura inédita inventada de memória; e a memória está aqui concebida não como a instância que retém, mas como a que suporta uma perda onde alguma coisa resta, um traço, um fragmento, que permite recolocar algo novo em jogo e transformar o mesmo em diferença. Este conceito, reabilitando a temporalidade e a historicidade do olhar, permitiu a Benjamin, segundo Didi-Huberman, refutar tanto a razão moderna (a razão cínica do capitalismo) quanto o irracionalismo arcaico preso à nostalgia das origens míticas.

A partir dos elementos abordados, podemos agora melhor explorar as conseqüências das diferentes formas de olhar propostas por Evgen Bavcar, através das figuras mitológicas greco-romanas acima descritas, tomando-as como paradigmas de distintos territórios existenciais. Dessa forma, o olhar ciclópico voltado para as formas míticas referidas a um passado que naturaliza o presente e que nos faz ver sempre o mesmo - alegoriza o território da ilusão de sempre podermos encontrar uma resposta tranqüilizadora no já conhecido, ao negar a cisão constitutiva da imagem, que carrega sempre um ponto de invisibilidade no visível. É o campo da crença numa verdade última a ser localizada num passado remoto ou num futuro distante, tão caro às concepções religiosas, que tem como conseqüência a negação do agora enquanto possibilidade de transformação, mesmo que na fulguração de constelações fugazes que, contudo, produzem modificações no mundo.

Já Ulisses, aqui simbolizaria o olhar da racionalidade instrumental - que nutre com tanta eficácia certo fazer científico - que nos parece voltado à tautologia, pretendendo só ver o evidente, confiando que suas lentes enxergam a coisa em si, como se o real pudesse ser apreendido diretamente. É o caso das concepções econômicas referidas tão somente a dados quantitativos como indicadores da marcha do progresso, desconsiderando brutalmente a realidade social em todas as suas nuances e produzindo os efeitos de dessubjetivação tão freqüentes em nosso tempo. É desde esta concepção existencial que podemos, por exemplo, ser tomados por consumidores, em vez de sujeitos, e o planeta, tratado como uma inesgotável fonte de recursos, elidindo, assim, tanto a ameaça de sua finitude quanto a nossa responsabilidade frente aos dejetos produzidos nesse processo: deste ponto de vista, o que primeiramente importa, quanto ao lixo que produzimos como consumidores, é que ele fique fora do nosso campo de visão.

Contudo, quando, qual Tirésias, podemos admitir que o obscuro, o vazio, a decrepitude, a morte, a perda e o resto igualmente compõem a existência, construímos um olhar que se estende também ao invisível, mas que somente a imagem que se dialetize em dupla distância - do que é e do que se perdeu - é capaz de figurá-la (DIDIHUBERMAN, 1998). Na esteira do pensamento benjaminiano, podemos pensar essa imagem como fruto de uma tensão dialética sem síntese possível que a harmonize, mas como lampejo que nos destitui de nossas certezas e nos deixa, na força de um instante, no limiar de um olhar, cara a cara com o que faz enigma. A análise de Foucault (2002a) do quadro As Meninas, de Velásquez, elucida brilhantemente a impossibilidade de a imagem mostrar todos os elementos que a integram, pois um vazio essencial referido àquilo que a funda está inelutavelmente indicado: para o autor, o ato de ver im- 
plica considerar a latência de uma ausência. Como uma cisão sempre reconduzida, a dialética joga com a contradição, não para resolvê-la, nem para entregar o mundo visível aos meios de uma retórica. Ela ultrapassa a oposição do visível e do legível num trabalho - no jogo - da figurabilidade. [...] Aqui não há portanto 'síntese' a não ser inquietada em seu exercício mesmo de síntese (de cristal): inquietada por algo de essencialmente movente que a atravessa, inquietada e trêmula, incessantemente transformada no olhar que ela impõe (DIDIHUBERMAN, 1998, p.117).

Como citado anteriormente, para Benjamin não existe imagem dialética sem trabalho crítico da memória no confronto com o que resta como indício de tudo o que foi perdido. Decorre daí que não se pode dizer nem que o passado ilumina o presente nem que o presente ilumina o passado, pois o passado se torna anacrônico enquanto o presente se apresenta reminiscente, num jogo sempre vivo em que a perda operacionaliza o desejo que impulsiona a experiência.

\section{A PASSAGEM PELA EXPERIÊNCIA E O ENCONTRO COM O INFORME}

A noção de experiência, que entendemos como potência para abertura de territórios existenciais mais ricos, não pode ser reduzida a meras vivências psicológicas. Esta diferença foi devidamente explicitada por Walter Benjamin (1985), em textos que demonstram o enfraquecimento - no sistema capitalista - da experiência (Erfahrung), em prol da experiência vivida (Erlebnis). Para este autor, a Erfahrung se situa na interface entre o que é coletivo e o que é singular, entre o que é do conhecimento estabelecido pela tradição e aquele que irrompe, fazendo um furo no que se afigura como perfeitamente estabelecido. Já a Erlebnis é característica do indivíduo solitário da modernidade, pois, como vimos, os modos de subjetivação próprios do capitalismo privilegiam formas de relação consigo pautadas em modos psicológicos individualizantes, nos quais o coletivo se constitui como mero pano de fundo. Referimo-nos, aqui, portanto, à experiência enquanto Erfahrung, como aquela que permite que algo nos aconteça, como diz Jorge Larrosa (2002), quando aponta o excesso de informação, de opinião, de trabalho, e a decorrente falta de tempo, como os fatores que a tornam tão rara hoje em dia. Não por acaso, uma das queixas mais prevalentes nos consultórios psicanalíticos é justamente a de que nada me acontece, mesmo quando os relatos apontam vivências significativas que, contudo, não são percebidas enquanto tais, demandando o testemunho de um terceiro para adquirirem valor. Para Benjamin (GAGNEBIN, 1994), uma vivência justamente só produz experiência quando envolve sua transmissão a outro, como ato de fala e testemunho que grava a marca singular de um narrador, numa narrativa que carrega o coletivo - o que se percebe em acordo com a acepção de Hannah Arendt (2001), de que apenas o compartilhamento da narração garante um estatuto especificamente humano à vida. Walter Benjamin atribui ao declínio das narrativas tradicionais o empobrecimento da transmissão da experiência na modernidade; mas nos deixou, não obstante, o precioso conselho (que não consiste em intervir de fora na vida de outrem, mas em fazer uma sugestão sobre a continuação de uma história que está sendo narrada ${ }^{4}$ ) de nos mantermos atentos às novas formas de narratividade que continuam a configurá-la. Pois o fato de reconhecermos a impossibilidade da sustentação da experiência tradicional, oriunda de organizações sociais espontâneas centradas no artesanato, não significa que devamos nos satisfazer com vivências individuais que nos privem da singularidade de verdades que só podem se constituir na força de suas relações (GAGNEBIN, 1994).

Precisando passar pelo corpo, a experiência constitui um saber inconsciente, um saber que não se sabe, como define Ana Costa (2001), ao afirmar que este só pode se atualizar na relação com o semelhante, e que sustenta o enigma de sempre se reatualizar exatamente onde fracassa e expõe o que é irrepresentável, relançando ad infinitum um jogo que explicita ao mesmo tempo nossa insuficiência e a do Outro. Entendemos a experiência, portanto, como um ato de corte que produz um intervalo, uma diferença com as formas preexistentes - e só o que pode sustentar um intervalo entre formas é o informe, como um momento lógico entre dois lugares. É, pois, só aí, no lugar do informe, que a certeza desfalece e algo novo pode tornar-se visível.

\section{NOTAS}

${ }^{1}$ Para Jean-Marie Gagnebin (1994) o conceito de alegoria de Walter Benjamin cava um túmulo tríplice: o do sujeito clássico e sua pretensão a uma identidade coerente de si mesmo; o dos objetos que se decompõem em fragmentos e deixam de ser depositários de estabilidade; e do processo mesmo da significação, já que o sentido para Benjamin surge da corrosão dos laços vivos e materiais entre as coisas.

${ }^{2}$ O que Guattari e Rolnik (1986) chamam de modo 
Mello, E.D.; Sousa, E.A.L."A experiência como intervalo para novas visibilidades"

de subjetivação capitalístico tem no sufixo 'ístico' a intenção de assinalar que essa produção não se restringe a sociedades capitalistas stricto sensu, mas configura um agenciamento de captura e modelização das subjetividades que o sistema Capitalista Mundial Integrado utiliza, na sua estratégia de absorção das diferenças, que, devidamente homogeneizadas, passam a se equivaler enquanto valor de mercadoria. Para estes autores, o que se busca num modo de subjetivação é a estabilização da subjetividade em um particular tipo de relação consigo, coextensiva às configurações do campo social engendradas pelas relações entre forças produtivas e meio de produção.

${ }^{3} \mathrm{O}$ conceito de "Outro", grafado em maiúscula, foi cunhado por Jacques Lacan para diferenciar o lugar do semelhante (outro) da dimensão da alteridade que, anterior e exterior ao sujeito, não obstante o determina. Refere-se, portanto, em última instância, à própria ordem da linguagem e da cultura.

${ }^{4}$ Como recuperado por Benjamin, em O Narrador (1995).

\section{REFERÊNCIAS}

ARENDT, Hannah. A condição humana. Rio de Janeiro: Forense Universitária, 2001.

BAUMAN, Zygmunt. O mal-estar da pósmodernidade. Rio de Janeiro: Jorge Zahar, 1998.

BAVCAR, Evgen. "Um outro olhar". Correio da APPOA, Porto Alegre, n. 93, p. 17-23, ago. 2001.

BENJAMIN, Walter. Obras escolhidas. São Paulo: Brasiliense, 1985. v. 1.

COSTA, Ana. Corpo e escrita: relações entre memória e transmissão de experiência. Rio de Janeiro: Relume-Dumará, 2001.

DELEUZE, Gilles. Conversações. São Paulo: Ed. 34, 1992.

DIDI-HUBERMAN, Georges. O que vemos, o que nos olha. São Paulo: Ed. 34, 1998.

FISCHER, Rosa Maria Bueno. "Problematizações sobre o exercício de ver: mídia e pesquisa em educação". Revista Brasileira de Educação, Rio de Janeiro, n. 20, p. 83-94, maio/ago 2002.

FOUCAULT, Michel. As Palavras e as Coisas. São Paulo: Martins Fontes, 2002a

FOUCAULT, Michel. Vigiar e punir: o nascimento da prisão. Petrópolis: Vozes, 2002b.
FOUCAULT, Michel. "La ética del cuidado de sí como práctica de la libertad". In: FOUCAULT, Michel. Estética, ética y hermenêutica. Barcelona: Paidós, 1999. Entrevista com H. Becker; R. FornetBetancourt, A. Gómez-Müller, 20 de janeiro de 1984.

GAGNEBIN, Jeanne Marie. História e narração em Walter Benjamin. São Paulo: Perspectiva, 1994.

GUATTARI, Félix; ROLNIK, Suely. Micropolítica: cartografias do desejo. Petrópolis: Vozes, 1986.

LARROSA, Jorge. "Notas sobre a experiência e o saber da experiência". Revista Brasileira de Educação, Rio de Janeiro, n. 19, p. 20-28, jan./abr. 2002.

MELMAN, Charles. Alcoolismo, delinquência, toxicomania; uma outra forma de gozar. São Paulo: Escuta, 1992.

NIETZSCHE, Friedrich. "O eterno retorno". In: Nietzsche. São Paulo: Nova Cultural, 1987. v.2. Col. Os pensadores.

TIMM, Liana. "Ima(r)gens". In: FONSECA, Tânia Maria Galli; KIRST, Patrícia Gomes (Org.). Cartografias e devires: a construção do presente. Porto Alegre: Editora da UFRGS, 2003.

Eliana Dable de Mello é Mestre em Psicologia Social e Institucional/UFRGS. Doutoranda em Educação/UFRGS. O endereço eltrônico da autora é: egieli@portoweb.com.br

Edson Luiz André de Sousa é Professor do PPG - Psicologia Social e Institucional e do Departamento de Psicanálise e Psicopatologia do Instituto de Psicologia da UFRGS, Professor do PPG - Artes Visuais do Instituto de Artes UFRGS. Doutor em Psicanálise e Psicopatologia pela Universidade de Paris VII. O endereço eletrônico do autor é: elsousa@plug-in.com.br

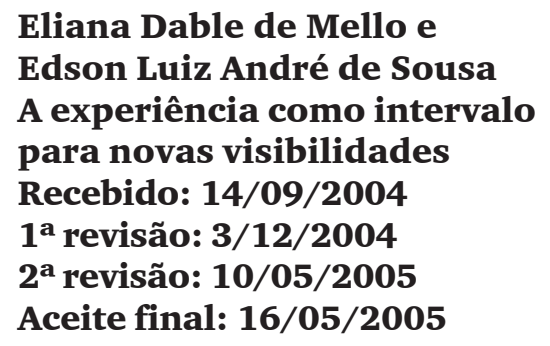

